American Journal of Infectious Diseases 8 (1): 13-18, 2012

ISSN 1553-6203

(C) 2012 Science Publications

\title{
Nutritional Status and Quality of Life of Women with HIV/AIDS
}

\author{
${ }^{1}$ Ananya Bhowmik, ${ }^{2}$ Padmini Ghugre, \\ ${ }^{2}$ Shobha Udipi and ${ }^{3}$ Subhasish Kamal Guha \\ ${ }^{1}$ Centre of Excellence in HIV, School of Tropical Medicine, \\ 108, Chittaranjan Avenue, Kolkata 700073, West Bengal, India \\ ${ }^{2}$ Department of Postgraduate Studies and Research in Home Science, \\ SNDT Women's University, Mumbai, 49. India \\ ${ }^{3}$ Department of Tropical Medicine and Nodal Officer, \\ Centre of Excellence in HIV, School of Tropical Medicine, \\ 108, Chittaranjan Avenue, Kolkata 700073, West Bengal, India
}

\begin{abstract}
Problem statement: HIV infection is a multisystem disorder which causes chronic infections that lead to profound immune- suppression. Women have always been a vulnerable section of the society. They are doubly vulnerable due to the HIV and malnutrition vicious cycle, which may affect their Quality Of Life (QOL). There are different literature reviews which suggest undernutrition, wasting due to HIV but it is important to know whether this under-nutrition affects their Quality Of Life (QOL) of these vulnerable women. Approach: This cross sectional study recruited female patients on antiretroviral therapy. Weight, height, grip strength, Tricep Skin Fold (TSF) and Mid Upper Arm Circumference (MUAC) were measured. Nutrient intake was calculated by $24 \mathrm{~h}$ recall and food frequency questionnaire. WHO QOL-HIV BREF was used to assess QOL. Results: Among 55 patients, $32(58.2 \%), 23(41.8 \%)$ were asymptomatic and symptomatic respectively. The mean adequacies of energy and protein for all the subjects were $57.56 \pm 21.89,61.27 \pm 28.50$ percent respectively. The Body Mass Index (BMI) of the symptomatic were significantly $(\mathrm{p}=0.009)$ lower than the asymptomatic subjects, the mean being $19.84 \pm 3.6\left(\mathrm{~kg} / \mathrm{m}^{2}\right)$, with $27.3 \%$ having BMI $<18.5$ $\left(\mathrm{kg} / \mathrm{m}^{2}\right)$. The mean TSF, MUAC, grip strength and hemoglobin level were $10.66 \pm 4.36 \mathrm{~mm}, 23.72 \pm$ $3.43 \mathrm{~cm}, 16.12 \pm 5.03 \mathrm{~kg}$ force and $10.8 \pm 1.3 \mathrm{~g} / \mathrm{dl}$ respectively. The scores of QOL were correlated positively with all the parameters of nutritional status. Grip strength and hemoglobin level were significantly correlated $(\mathrm{p}=0.01)$ with the scores of four and five domains of QOL respectively. Conclusion: Dietary intake was inadequate, which affected the nutritional status. Conservation of muscle mass and maintenance of hemoglobin levels may improve QOL in HIV infected women. Thus there is a need for nutritional counseling and other nutritional intervention.
\end{abstract}

Key words: Nutritional status, dietary intake, quality of life, HIV/AIDS, women

\section{INTRODUCTION}

Malnutrition has been one of the most common hallmarks of HIV disease for years. It is thought to play a synergistic role in immunosuppressant initiated by HIV and has been proposed to be an independent risk factor for HIV disease progression (Smith, 1998). Protein Energy Malnutrition (PEM) and wasting is common in HIV/AIDS patients. In Rajasthan, 67\% HIV positive patients were suffering from PEM (Dutta et al.,
2002). This is accompanied with an increase in Resting Energy Expenditure (REE). There is a slight increase of REE in the asymptomatic phase, a great increase in people with AIDS and greatest in those with active secondary infection (Batterman, 2005).

The micronutrient status of the patients is also affected by HIV/AIDS and its medication. Among these micronutrients vitamin A, Vitamin $\mathrm{C}$, selenium, Zinc, Calcium and iron are moderately affected (Tang et al., 2005). In a chronic disease like HIV/AIDS the Quality

Corresponding Author: Ananya Bhowmik, Centre of Excellence in HIV, School of Tropical Medicine, 108,

Chittaranjan Avenue, Kolkata 700073, West Bengal, India, Tel: +919830544071/+913322573461 
Of Life (QOL) of the patients form an important aspect. WHO has defines QOL as individuals' perception of their position in life in the context of their culture and value system in which they "live and in relation to their goals, standards, expectations and concerns" (WHOQOL HIV Group, 2004).

The relation between nutritional status and quality of life is not well defined. There is evidence of different symptoms like chemosensory complaints of both smell and taste leading to inadequate nutrient intake and reducing the quality of life of HIV/AIDS patients (Heald et al., 1998). However wasting also reduces the quality of life in HIV/AIDS patients (Testa and Lenderking, 1999).

It is evident that the relation between nutritional status and quality of life still remains to be unfolded. Therefore the objective of the study was to assess the nutritional status, quality of life and to examine if there is any relationship between them. Women were selected as subjects as they were a vulnerable group and incidence of HIV infection was increasing among them.

\section{MATERIALS AND METHODS}

The present study was undertaken to study the nutritional status, dietary intake and quality of life of women with HIV/AIDS.

Sample selection: Fifty five HIV positive female patients in the age group of 20-45 years were recruited. The patients were recruited in a span of one month from Antiretroviral Therapy Centre in Calcutta School of Tropical Medicine, Kolkata. All Subjects who were previously diagnosed to have HIV infection and were taking Anti Retroviral Therapy (ART) and were willing to participate in the study were included. A written consent was taken from each of the subjects and they were assured of complete confidentiality before administering the interview schedule. The study was a cross sectional study and the subjects were contacted in the hospital. The data was collected by interviewing the patient in local languages.

Tools for data collection: The interview schedule was prepared to obtain information. The interview schedule was used in pilot study conducted among HIV positive women and after pilot testing, a few local foods were added to the food frequency questionnaire. Weight, height and Mid Upper Arm Circumference (MUAC) (Shils, 2006) were measured by standard methods. Grip strength and Tricep Skin Fold (TSF) (Mahan and
Escott-Stump, 2004) were measured with grip strength dynamometer from OG Gileen Company Limited, Japan and Harpenden Caliper respectively.

Information on dietary intake was collected by $24 \mathrm{~h}$ recall method and dietary pattern was collected by food frequency questionnaire. $24 \mathrm{~h}$ dietary recall was taken with the help of katoris, spoons, glasses which were standardized with commonly consumed recipes. Standardized models of chapatti, bhakri, fruits, snacks items were prepared and used for accurate data. To assess the quality of life of the patients WHO QOLHIV BREF developed by the WHO group in 2002. World Health Organization HIV/AIDS quality of life Group, 2002 was used with a minor modification. This questionnaire had 32 facets and 6 domains.

Data analysis: BMI was calculated from the height and weight using the following formula:

BMI $=$ Weight $(\mathrm{kg}) /$ Height $^{2}(\mathrm{~m})$

All the food consumed was converted to raw weight and nutrient intakes were calculated with the help of food consumption Table 1 (Gopalan et al., 1989). The intakes were compared with Recommended Dietary Allowance (RDA) for the nutrients for HIV negative adult Indian women (Gopalan et al., 1989 and nutritional adequacy was calculated in terms of percentage.

Nutritional adequacy $\%=\frac{\text { Nutrient Intake } \times 100}{\text { RDA for nutrient }}$

It must however be noted that the RDA of HIV positive women is more than normal HIV negative women owing to the catabolic nature of the disease.

Scoring of the questionnaire was done according to the WHO format World Health Organization HIV/AIDS quality of life group, 2002.

\begin{tabular}{llll}
\multicolumn{4}{l}{ Table 1: Clinical parameters of subjects } \\
$\begin{array}{l}\text { Clinical } \\
\text { parameters }\end{array}$ & $\begin{array}{l}\text { Total } \\
(\mathrm{n}=55)\end{array}$ & $\begin{array}{l}\text { Asymptomatic } \\
(\mathrm{n}=23)\end{array}$ & $\begin{array}{l}\text { Symptomatic } \\
(\mathrm{n}=32)\end{array}$ \\
\hline $\begin{array}{l}\text { Duration of } \\
\text { Infection (Month) }\end{array}$ & $18.94 \pm 16.36$ & $18.93 \pm 14.5$ & $18.95 \pm 19.0$ \\
$\begin{array}{l}\text { Duration of } \\
\text { ART (Month) }\end{array}$ & $12.47 \pm 12.87$ & $14.31 \pm 13.11$ & $9.1 \pm 12.35$ \\
$\begin{array}{l}\text { CD4 count } \\
\text { Cells } \mu L^{-1}\end{array}$ & $243.42 \pm 151.75$ & $299.03 \pm 166.37$ & $166.04 \pm 82.34$ \\
CD4/CD8 & $0.62 \pm 0.65$ & $0.72 \pm 0.72$ & $0.50 \pm 0.53$ \\
\hline Source: Primary
\end{tabular}

Source: Primary survey, 2011 Kolkata 
Table 2: Daily mean nutrient adequacy

\begin{tabular}{|c|c|c|c|}
\hline \multirow[b]{2}{*}{$\begin{array}{l}\text { Nutrient } \\
\text { adequacy (\%) }\end{array}$} & \multicolumn{3}{|l|}{ Subjects } \\
\hline & $\begin{array}{l}\text { Total } \\
\text { Mean } \pm \text { S.D. }\end{array}$ & $\begin{array}{l}\text { Asymptomatic } \\
\text { Mean } \pm \text { S.D. }\end{array}$ & $\begin{array}{l}\text { Symptomatic } \\
\text { Mean } \pm \text { S.D. }\end{array}$ \\
\hline Energy & $57.56 \pm 21.89$ & $64.25 \pm 19.46$ & $48.25 \pm 22.06$ \\
\hline Protein & $61.27 \pm 28.50$ & $69.23 \pm 26.08$ & $48.25 \pm 22.06$ \\
\hline Calcium & $48.83 \pm 56.03$ & $59.09 \pm 65.76$ & $38.58 \pm 44.53$ \\
\hline Iron & $22.78 \pm 11.52$ & $22.85 \pm 08.99$ & $22.68 \pm 14.55$ \\
\hline$\beta$ Carotene & $22.48 \pm 49.65$ & $26.43 \pm 62.88$ & $16.99 \pm 20.66$ \\
\hline Vitamin C & $50.32 \pm 46.32$ & $55.37 \pm 48.17$ & $43.32 \pm 43.67$ \\
\hline
\end{tabular}

Source: Primary survey, 2011 Kolkata

Statistical analysis: The data were classified and tabulated. The results were expressed in terms of ranges percentages, means, standard deviation and median (in some cases). The other statistical analyses used were $\mathrm{T}$ test for comparing asymptomatic and symptomatic subjects and Pearson's correlation to correlate two variables. Cranach's Alpha was used to find out the reliability of the quality of life questionnaire.

\section{RESULTS}

The mean age of the study population was $30.5 \pm 6$ years and more than half $(31 ; 56.4 \%)$ of the subjects were below secondary level of education. Only 17 $(24.5 \%)$ subjects were employed outside the house. Among the working women, most of them (12women) were either widow or separated and had the responsibility to support their family. One third of the total study population was widowed and separated which indicated the heavy responsibilities that these women had to bear alone without any support apart from their HIV positive status. Eighty percent of women in the present study had at least one child and the mean number of children and adults in the family were $1.47 \pm 1.05$ and $1.31 \pm 1.37$ respectively. However the mean income of the family of the subjects was Rs $39156.36 \pm 40693.08$ per annum.

The World Health Organization clinical stage classification (NAIDSCOI, 2007) was used to classify the patients into 2 groups: asymptomatic (corresponding to stage 1 of WHO classification) and symptomatic (stage 2-4). Table 1 shows that symptomatic women have lower CD4 counts than their

Opportunistic infections have been the hallmark for the clinical diagnosis of AIDS. Information regarding opportunistic infection and chronic illness was collected from the case history report. In the present study most prevalent $(34.5 \%)$ opportunistic infection was Tuberculosis. The second most prevalent was chronic dermatitis and oral candidacies followed by persistent fever and persistent diarrhea while bronchitis and AIDS dementia complex were less common. As observed from Table 2 both energy and protein adequacy was low. Unlike protein and energy the fat intakes of the subjects were moderate; it comprised of $27.56 \%$ of the mean calorie intake. The mean intake of $\beta$ Carotene was the lowest followed by iron, calcium vitamin $\mathrm{C}$.

Different factors like anorexia, nausea, vomiting, food allergy, taste alteration and pain in swallowing, contributed to low food intake. Significant negative correlation was found between diarrhea, tuberculosis, dementia, dysentery and constipation and nutrient intake. The heights of both asymptomatic and symptomatic patient were similar (Table 3). Unlike height, the mean weight of the symptomatic subjects was lower than the asymptomatic ones, results being statistically significant $(\mathrm{p}=0.009)$. The BMI of the symptomatic group was also significantly lower in comparison to the asymptomatic subjects $(\mathrm{p}=0.013)$ but in case of MUAC and TSF the results were not statistically significant. When subjects were distributed as per WHO categories majority $26(47.3 \%)$ of the subjects had mild anemia (Hob 10-11.9 $\mathrm{gm} \mathrm{dL}^{-1}$ ). This was followed by 19 (34.5\%) moderately anemic (Hob 7- $9.9 \mathrm{gm} \mathrm{dL}^{-1}$ ) patients.

It is important to note that the mean hemoglobin level was lower in symptomatic than asymptomatic subjects and this difference was statistically significant $(p=0.006)$. Nutritional status was influenced in this study by different factors like nutrient intake, presence of opportunistic infections and chronic disease.

Nutritional grade improved with increase in energy adequacy of the subjects. The quality of life scores were reported in six domains and the total score and the scores of the all the domains (except social relationship) were higher for asymptomatic subjects but the difference was not statistically significant for any of the above. The mean score was highest in social domain and lowest in psychological domain (Table 4). After the data collection, the reliability of this questionnaire was tested with the help of Cranach's Alpha and the score for 32 items was 0.872 .

The data on illness in the last 15 days revealed cough and cold to be the most common (41.8\%) symptom followed by dry itching skin (43.6\%), cough and fever $(41.8 \%)$, abdominal pain, menstrual disorder and night sweat. asymptomatic counterpart. This difference of CD4 count was significant at the level of $0.05(\mathrm{p}=0.018)$. The less common morbidity data included body ache, tongue lesion, diarrhea, mouth sore, dysentery, constipation and STI. 
Am. J. Infect. Dis., 8 (1): 13-18, 2012

Table 3: Nutritional status of subjects

\begin{tabular}{|c|c|c|c|c|c|c|}
\hline \multirow{3}{*}{$\begin{array}{l}\text { Anthropometric } \\
\text { measure }\end{array}$} & \multicolumn{6}{|c|}{ Subjects } \\
\hline & \multicolumn{2}{|l|}{ Total } & \multicolumn{2}{|c|}{ Asymptomatic } & \multicolumn{2}{|c|}{ Symptomatic } \\
\hline & Mean & SD & Mean & $\mathrm{SD}$ & Mean & SD \\
\hline Weight $(\mathrm{kg})$ & 45.49 & 8.54 & 47.98 & 8.55 & 42.02 & 7.37 \\
\hline Height $(\mathrm{cm})$ & 151.45 & 5.37 & 151.53 & 5.01 & 151.33 & 5.94 \\
\hline BMI $\left(\mathrm{kg} \mathrm{m}^{-2}\right)$ & 19.84 & 3.60 & 20.85 & 3.24 & 18.43 & 3.67 \\
\hline T. S. F. (mm) & 10.66 & 4.36 & 11.19 & 4.52 & 9.93 & 4.33 \\
\hline $\operatorname{MUAC}(\mathrm{cm})$ & 23.72 & 3.43 & 24.34 & 2.57 & 22.87 & 4.27 \\
\hline Grip strength ( $\mathrm{kg}$ force) & 16.12 & 5.03 & 16.90 & 5.15 & 15.04 & 4.76 \\
\hline $\mathrm{Hb}\left(\mathrm{g} \mathrm{dL}^{-1}\right)$ & 10.27 & 1.57 & 10.75 & 1.30 & 9.60 & 1.69 \\
\hline
\end{tabular}

Source: Primary survey, 2011 Kolkata

Table 4: Quality of life scores of subjects

\begin{tabular}{|c|c|c|c|c|}
\hline \multirow[b]{2}{*}{ Domains } & \multirow[b]{2}{*}{ Total score } & \multicolumn{3}{|c|}{ Mean score $( \pm$ S.D $)$} \\
\hline & & Total & Asymptomatic & Symptomatic \\
\hline Physical & 20 & $11.5 \pm 4.26$ & $12.28 \pm 4.12$ & $10.57 \pm 4.33$ \\
\hline Psychological & 20 & $10.18 \pm 3.40$ & $10.67 \pm 3.55$ & $9.49 \pm 3.290$ \\
\hline Level of independence & 20 & $11.07 \pm 3.48$ & $11.53 \pm 3.27$ & $10.43 \pm 3.74$ \\
\hline Social relationships & 20 & $12.58 \pm 3.81$ & $11.78 \pm 3.79$ & $13.70 \pm 3.64$ \\
\hline Environment & 20 & $11.82 \pm 2.68$ & $11.89 \pm 3.02$ & $11.71 \pm 2.19$ \\
\hline $\begin{array}{l}\text { Spirituality / Religion / } \\
\text { Personal beliefs (SRPB) }\end{array}$ & 20 & $10.22 \pm 3.45$ & $10.28 \pm 3.38$ & $10.13 \pm 3.62$ \\
\hline Total score (raw) & 160 & $86.93 \pm 17.39$ & $88.4 \pm 18.38$ & $84.83 \pm 16.08$ \\
\hline
\end{tabular}

Source: Primary survey, 2011 Kolkata

Table 5: correlation between nutritional status and quality of life

\begin{tabular}{|c|c|c|c|c|c|c|c|}
\hline \multirow[b]{2}{*}{ Nutritional status } & \multicolumn{7}{|c|}{ Quality of life domains } \\
\hline & Total score & Physical & Psycho-logical & Independence & Social relation & Environment & SRPB \\
\hline Weight (Kg) & $0.476^{* *}$ & $0.268^{*}$ & $0.464 * *$ & $0.395^{* *}$ & 0.159 & 0.161 & 0.022 \\
\hline Height $(\mathrm{cm})$ & 0.014 & 0.150 & 0.028 & -0.167 & -0.045 & -0.022 & -0.004 \\
\hline $\operatorname{BMI}\left(\mathrm{kg} / \mathrm{m}^{2}\right)$ & $0.454^{* *}$ & 0.197 & $0.435^{* *}$ & $0.435^{* *}$ & 0.178 & 0.175 & 0.011 \\
\hline Grip strength & & & & & & & \\
\hline (kgforce) & $0.457 * *$ & $0.214 *$ & $0.451 * *$ & $0.488 * *$ & 0.034 & $0.256 *$ & 0.112 \\
\hline MUAC $(\mathrm{cm})$ & $0.237 *$ & 0.073 & 0.216 & $0.288^{*}$ & 0.214 & 0.050 & -0.105 \\
\hline Skin fold $(\mathrm{mm})$ & $0.356^{* *}$ & 0.187 & $0.327 * *$ & $0.340^{* *}$ & $0.257 *$ & 0.012 & 0.054 \\
\hline $\begin{array}{l}\text { Hemoglobin } \\
\left(\mathrm{g} \mathrm{dL}^{-1}\right)\end{array}$ & $0.478 * *$ & $0.246^{*}$ & $0.394 * *$ & $0.338^{* *}$ & 0.194 & $0.334 * *$ & $0.239^{*}$ \\
\hline
\end{tabular}

The correlation between nutritional status and quality of life is given in Table 5. Here all the parameters, except height, were positively and significantly correlated with the total score for quality of life, with the level of significance being 0.01 for BMI, grip strength, skin fold, weight and hemoglobin level. Among different parameters, grip strength and hemoglobin level were significantly correlated with the scores of four and five domains respectively. Thus conservation of muscle mass and maintenance of hemoglobin level improve quality of life in HIV infected women.

\section{DISCUSSION}

The nutrient intake of the patients was very low. This is of concern since the requirement of such patients is $10-15 \%$ more than the normal RDA in case of energy and $1.5-2 \mathrm{gm} \mathrm{kg}^{-1} \mathrm{day}^{-1}$ of ideal bodyweight in case of protein (Mahan and Escott-Stump, 2004). Energy and protein deficit leads to morbidity and mortality due to opportunistic infection (Forrester et al., 2002). Vitamin C like calcium had less than recommended intake but its adequacy was more than the rest of the micronutrients. This can be attributed to the increased intake of guava and sweet lime in this study as observed from the food frequency results.

In the present study most of the subjects had family support and came to the clinic with their care giver. In the study by (Wig et al., 2006) in North India social domain also received highest scores. This was the only domain in which the symptomatic patients scored higher than the asymptomatic; this can be attributed to the greater attention they received from their care givers due to their poor health. Disease morbidity usually 
resulted in higher deterioration of psychological domain of QOL. Further studies suggested that higher income and education lead to better coping strategies and since the study population was a representation of lower income group and majority of the women were below secondary level of education, the coping strategy was not good enough. This could be explained probably due to lack of appropriate counseling of the patients. (Jirathitikal et al., 2004).

In case of HIV, nutrition is an important factor which affects quality of life. Better nutrition is one of the key factors which helps in delaying AIDS in an HIV infected individual, thus leads to a better quality of life. This was evident by the correlation of nutritional status with quality of life. The weight was positively and significantly correlated with physical domain. Studies suggest that if the weight of the patient increases the quality of life of the patient also increases (Huang et al., 2006). This may be because decreased weight is an important marker of disease progression and symptom status which affects physical domain. Weight was also correlated with psychological and independence domain. Psychological domain comprises of body image which is affected by decreased weight. Decrease in weight among Indian women of the lower socio economic group makes them feel that they are unattractive and this leads to a decrease in psychological domain scores. In case of independence domain lower weight is related to increased disease progression which leads to decreased activity, mobility and work capacity which comprises this domain.

BMI per se was significantly correlated with total score, psychological and independence domain. According to a study women feel that being underweight will disclose their HIV positive status. This disclosure might lead to shame and discrimination in the community due to social stigma of this disease (Sayer et al., 2006). Thus a low BMI may lead to decreased scores in psychological domain and total scores. Though there is a scarcity of studies relating grip strength and quality of life in HIV/AIDS, it has been correlated with old age. Lower grip strength is associated with reduced health related quality of life in older men and women. This does not appear to be explained by age, size, physical activity or co morbidity and may reflect the link between sarcopaenia and generalised frailty. HIV/AIDS is characterized by a decrease in lean body mass (LBM) or muscle mass which is similar to Sarcopaenia in old age.

Better MUAC and skin fold thickness might lead to better mobility, work capacity and activities of daily life. Dependence on medication was also a facet of independence domain and in the present study all the patients were under HAART. It is evident in several researches (McDermott et al., 2001; Heath et al., 2002) that HAART leads to lipodystrophy, which may have led to a decreased skin fold and MUAC measurements. Hemoglobin level was positively correlated strongly with physical domain which comprises of fatigue and energy and it is known that fatigue and breathlessness is one of the common symptoms of anemia. A study claimed that an improvement in the hemoglobin level in an HIV/AIDS patient increased her quality of life scores especially in the physical domain from 35 to 43.9 using MOS instrument for measuring quality of life (Volberding, 2002).

\section{CONCLUSION}

It is evident from the results of the present study that the stage of infection affects the dietary intake, nutritional status and quality of life of these women. Further HIV infection along with morbidity affects the dietary intake which along with disease condition in turn influences the nutritional status of the subjects. Lastly all domains of quality of life are affected by nutritional status in this study especially MUAC and hemoglobin. Therefore intervention need to be planned aiming to improve nutritional status primarily MUAC and hemoglobin to improve the quality of life of these women.

\section{ACKNOWLEDGEMENT}

This study was supported by Tropical School of Medicine (Kolkata) and the patients who took part in the study.

\section{REFERENCES}

Smith, R.A., 1998. Encyclopedia of AIDS: A Social, Political, Cultural and Scientific Record of the HIV Epidemic. 2nd Edn., Taylor and Francis, USA., ISBN-10: 1579580076, pp: 601.

Dutta, K., B. Sati, D.K. Garg, S.D Purohit and A. Haag et al., 2002. Nutritional profile of HIV/AIDS patients from Rajasthan, India. International AIDS Socity.

Batterman, M.J., 2005. Investigating heterogeneity in studies of resting energy expenditure in persons with HIV/AIDS: A meta-analysis. Am. J. Clin. Nutr., 81: 702-713.

Tang, M.A., J. Lanzillotti, K. Hendricks, J. Gerrior and M. Ghosh et al., 2005. Micronutrients: current issues for HIV care providers. AIDS, 19: 847-861. PMID: 15905665 
WHOQOL HIV Group, 2004. WHOQOL-HIV for quality of life assessment among people living with HIV and AIDS: Results from the field test. AIDS Care, Psychol. Socio-Med. Aspects AIDS/HIV, 16: 882-889. DOI: 10.1080/09540120412331290194

Heald, A.E., C.F. Pieper and S.S. Schiffman, 1998. Taste and smell complaints in HIV-infected patients. AIDS, 12: 1667-1674. PMID: 9764787

Testa, M.A and W.R. Lenderking, 1999. The impact of AIDS-associated wasting on quality of life: Qualitative issues of measurement and evaluation. J. Nutr., 129: 282S-289S. PMID: 9915916

Shils, M.E., 2006. Modern Nutrition in Health and Disease. 10th Edn., Lippincott Williams and Wilkins, Philadelphia, ISBN-10: 0781741335, pp: 2069.

Mahan, L.K and S. Escott-Stump, 2004. Krause's Food, Nutrition and Diet Therapy. 11th Edn., WB Saunders, Philadelphia, ISBN-10: 0721697844, pp: 1321.

Gopalan, C., B.V.R. Sastri and S.C. Balasubramanian, 1989. Nutritive Value of Indian Foods. 1st Edn., National Institute of Nutrition, Hyderabad, India, pp: 156.

NAIDSCOI, 2007. Antiretroviral Therapy Guidelines for HIV-Infected Adults and Adolescents Including Post-Exposure Prophylaxis. 1st Edn., National AIDS Control Organisation, Ministry of Health and Family Welfare, New Delhi, pp: 126.

Forrester, J.E., D. Spiegelman, E. Tchergen, T.A. Knox and S.L. Gorbach, 2002. Weight loss and bodycomposition changes in men and women infected with HIV. Am. J. Clin. Nutr., 76: 1428-1434.
Wig, N., R. Lekshmi, H. Pal, V. Ahuja and C.M. Mittal, 2006. The impact of HIV/AIDS on the quality of life: A cross sectional study in north India. Indian J. Med. Sci., 60: 3-12. DOI: 10.4103/00195359.19670

Jirathitikal, V., O. Metadilogkul and A.S. Bourinbaiar. 2004. Increased body weight and improved quality of life in AIDS patients following V-1 Immunitor administration. J. Eur. Clin. Nutr., 58: 110-115. DOI: $10.1038 /$ sj.ejcn.1601756

Huang, J.S., S. Harrity, D. Lee, K. Becerra and R. Santos, 2006. Body image in women with HIV: A cross-sectional evaluation. AIDS Res. Ther., 3: 711. DOI: $10.1186 / 1742-6405-3-17$

Sayer, A.A., H.E. Syddall, H.J. Martin, E.M. Dennison and H.C. Roberts et al., 2006. Is grip strength associated with health-related quality of life? Findings from the Hertfordshire cohort study. Age Ageing, 35: 409-415. DOI: 10.1093/ageing/afl024

McDermott, A.Y., A. Shevitz, T. Knox, R. Roubenoff and J. Kehayias et al., 2001. Effect of highly active antiretroviral therapy on fat, lean and bone mass in HIV-seropositive men and women. Am. J. Clin. Nutr., 74: 679-86.

Heath, K.V., R.S. Hogg, J. Singa, K.J. Chan and M.V. O'Shaughnessy et al., 2002. Antiretroviral treatment patterns and incident HIV-associated morphologic and lipid abnormalities in a population-based cohort. JAIDS, 30: 440-447.

Volberding, P., 2002. The impact of anemia on quality of life in human immunodeficiency virus-infected patients. J. Infect. Dis., 185: S110-S1144. 